\title{
Efficient Synthesis of a Conformationally Rigid Polymer Based on myo-Inositol Carbonate
}

\author{
Hye-Jin Lee and Tae-Hyun Kim" \\ Department of Chemistry. University of Incheon. Incheon 402-749, Korea. "E-mail: thim@incheonackr \\ Received December 28,2005
}

Key Words : myo-Inositol carbonate, Metal-chelating ligand, Conformationally rigid polymer

Compounds having three syn-axial hydroxyl groups on a six membered ring draw an interest due to their ability to form complexes with many cations. ${ }^{1 / 2}$ The steric requirements of the cyclohexane polyols to fom complexes with cations are, however, rather strict and only a few such compounds with three syn-axial hydroxyls, including cisinositol, were known. ${ }^{3-8}$ Moreover, none of these compounds is readily available, especially in large scales. Recently, synthesis of the readily available mo-inositol 4,6-carbonate 1 with three hydroxyl groups at the axial position on a cyclohexane was reported. ${ }^{9}$ To our knowledge, this was the first example of the conformationally rigid cyclohexane polyols using the readily available mo-inositol. Here, the carbonate group was introduced as a short bridge between $\mathrm{O}-4$ and $\mathrm{O}-6$ of mo-inositol, holding the confomation of the cyclohexane that has three axial hydroxyl groups. Other bridges, including a methylene group, were known to have difficulties to be placed between the two axial hydroxyl groups. ${ }^{1 !}$

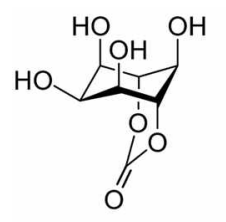

1

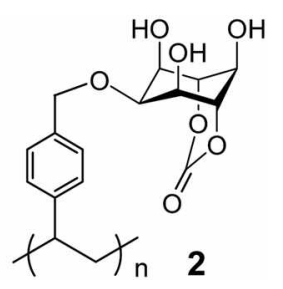

We were interested in developing a novel inositol-based polymer with an organized backbone and oriented functional groups. It was expected that the oriented functional groups. originated from the structurally rigid inositol structure, would be responsible for the desired interaction with the substrate, cations in this case, whereas the polymer backbone provide a structural framework and mechanical stability. ${ }^{11-16}$ Polymeric analogues of inositol should, therefore, be useful as a metal chelating ligand since polymers are generally valued as chelating agents due to their advantages of easy use and removal after chelation.
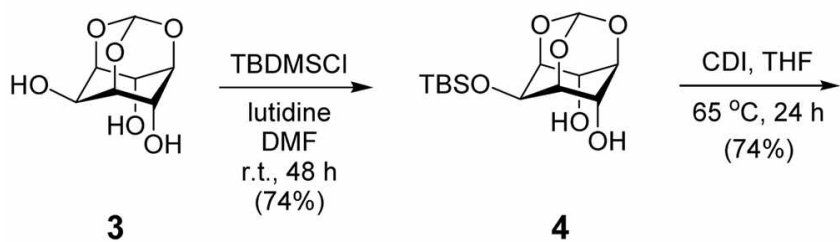

Scheme 1. Synthetic route to mo-inositol 4,6-carbonate.
We report herein an efficient synthesis of a conformationally rigid inositol carbonate-based polymer 2 to deliver such features. Although the reported procedure by Angyal, was efficient to prepare the inositol carbonate itself (Scheme 1), it seemed difficult to functionalize for further derivatization (vide siffio), We have, therefore, developed an altemative synthetic route to mwo-inositol 4,6-carbonate with a polymerizable group at the equatorial position and successfully polymerized to afford a conformationally rigid polymer as a novel metal-chelating ligand.

Following the literature procedure, ${ }^{\text {P.1 }}$ the silylated inositol carbonate 5 was first prepared (Scheme 1). Deprotection of the silyl group, however, in order to introduce a polymerizable group at the equatorial hydroxyl group of the cyclohexane, using a standard basic fluoride ion (e.g. TBAF) also cleaved the carbonate group. None of the silyl deprotection methods attempted proved to be effective. Although the desired inositol carbonate with a free equatorial hydroxyl group 6 was obtained by a partial cleavage of the silyl group during the strongly acidic deprotection of the orthoformate group, the yield was rather too low. ${ }^{18}$ The poor solubility of 6 also made futher derivatization of this compound difficult.

Altematively, the mo-inositol orthoformate 3 was first diallylated to give the 4,6-diallyl inositol derivative 7 (Scheme 2). The preferential allylation of the axial hydroxyls, in the presence of the less hindered 2-hydroxyl group, was possible due to the stabilizing effect from the neighboring axial group in $\mathbf{3}$ as the $\mathrm{Na}^{+}$counterion is chelated by the second axial $\mathrm{OH}$ group. ${ }^{19}$ Although the yield for the direct diallylation of the axial hydroxyl groups was rather low $(36 \%)$, it innecessitated the tedious protection and deprotection of the more reactive equatorial hydroxyl group, using TBDMSCl, a typically used expensive protecting agent for this system. The diallyl groups in 7 were then isomerized to the enol ethers 8 using Wilkinson's catalyst. ${ }^{\text {ij }}$ Introduction of the styrenyl moiety as a polymerizable group to the free alcohol, followed by hydrolysis of the enol ethers using mercury(II) acetate ${ }^{21}$ produced the diol 9 in $84 \%$ yield
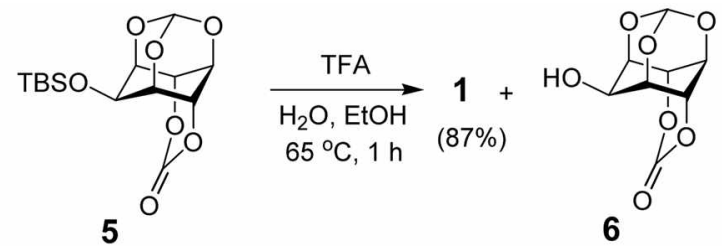

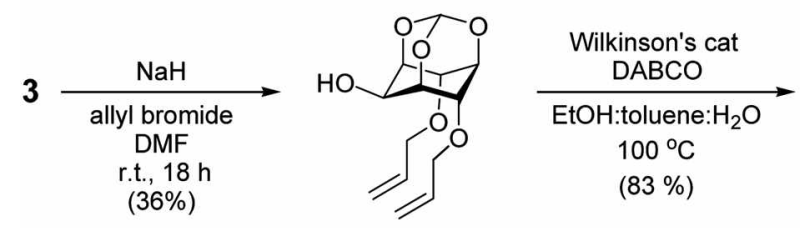

7

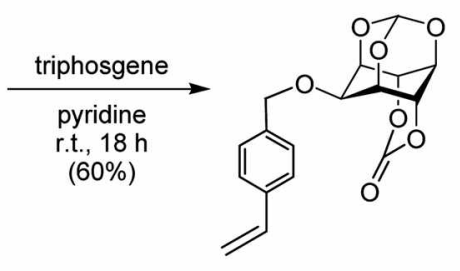

10

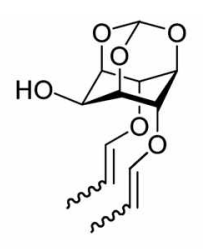

8

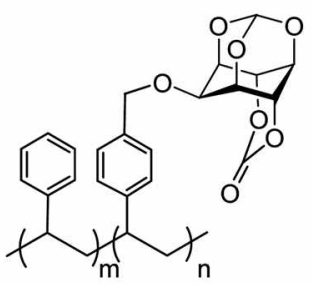

11
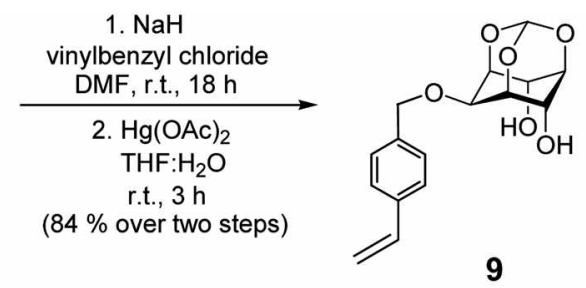

9

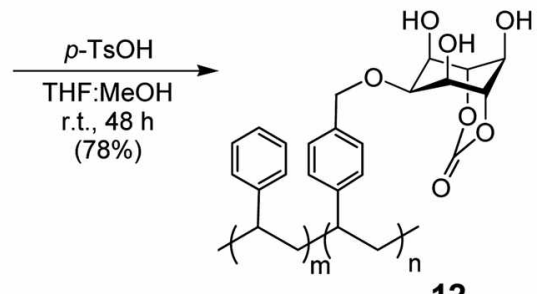

12

Scheme 2. Synthesis of mo-inositol 4,6-carbonate-based polymer

over two steps. Treatment of 9 with triphosgene in the presence of pyridine afforded the carbonate $\mathbf{1 0} \mathrm{in}$ a moderate yield $(60 \%)$. Formation of the carbonate using CDI, as used the literature, ${ }^{2}$ was not very effective for our system. The monomer 10 was expected to fit the need for the preparation of well-defined synthetic polymers, arranging functional groups in a predetermined fashion, and it can be prepared in a multigram scale. Copolymerization of the mro-inositol carbonate 10 with styrene was carried out at $65^{\circ} \mathrm{C}$ in THF with $\mathrm{AIBN}$ as a radical initiator to give the inositol polymer $11 \mathrm{in} 80 \%$ yield and molecular weight of $11,000\left(\mathrm{M}_{\mathrm{n}}\right) .^{22^{2}}$

Finally, removal of the orthoformate group in polymer 11 was accomplished in the presence of $p-\mathrm{TsOH}$ in $78 \%$ yield (Scheme 2). The structure determination of the deprotected polymer 12 was carried out by the ${ }^{13} \mathrm{C}$ NMR spectrum, and showed disappearance of the signal comesponding to the orthofomate carbon $(\delta=102)$, whilst preserving the carbonate signal $(\delta=145)$. The IR spectrum of 12 also showed the maintenance of the carbonate group at 1750 $\mathrm{cm}^{-1}$, and a strong signal due to the free hydroxyls appeared at $3440 \mathrm{~cm}^{-1} .33$ In addition, the spectroscopic properties of the inositol ring atoms in 12 were very similar to those of other precursors, indicating that the conformation of the inositol ring was maintained. ${ }^{23}$ The preliminary metal binding studies using polymer 12 were carried out by comparing the IR spectra of 12 with polychelate (12 with $\mathrm{CaCl}_{2}$ ). The region assigned to the hydroxyl groups of the polychelate, compared with the parent polymer ligand $\mathbf{1 2}$, exhibited broadness toward lower wavenumbers, which is ascribed to the involvement of the hydroxyl groups in metal-chelation. ${ }^{2-}$

In conclusion, we have successfully synthesized the polystyrene carying a conformationally rigid mo-inositol substituent as a possible metal-chelating ligand. We are further investigating the metal binding properties of this polymer and its applicability to the practical use such as molecular imprinting.

Acknowledgment. This work was generously supported by the faculty research fund of Incheon University in 2004.

\section{References}

${ }^{\dagger}$ All new compounds exbibited satisfactory analytical data, which included IR, "H and ${ }^{12} \mathrm{C}$ NMR spectra, and high-resolution mass spectra.

1. Angyal, S. J. Atst. J. Chem. 2000, 53,567, and references therein.

2. Hegetschweiler, K.: Ghisletta, M.: Fassler, T. F.: Nesper, R.; Schmalle, H. W.; Ribs, G. Inorg. Chem. 1993, 32, 2032.

3. Anderson, J. E.; Angyal, S. J.; Craig. D. C. J. Chem. Soc. Perkin Trons. $21997,729$.

4. Angyal, S. J.: Greeves, D.: Litllemore, L. Atst. J. Chem. 1985, is, 1561.

5. Paquette, L. A.; Selsaraj, P. R.; Keller, K. M.; Brodbelt, J. S. Tetrahedron 2005, 61,231.

6. Paquette, L. A.; Tae, J. J. Ant. Chem. Soc. 2001, $/ 23,4974$.

7. Tae, J.; Rogers, R. D.; Paquette, L. A. Org, Letr. 2000, 2, 139.

8. Kim, T.-H.; Holmes, A. B. J. Chen. Soc, Perkin Trons. / 2001, 2524.

9. Angyal, S. J. Carbohtrir. Res. 2000, 325, 313.

10. Das, T.: Shashidhar, M. S. Cambolndr: Res. 1997, 297, 243.

11. Wulfi, G. Angen: Chem. Wh. Ed. Engl. 1989, 28, 21.

12. Kaliyappan, T.; Kamna, P. Prog Polm. Sci. $2000,25,343$.

13. Sherrington, D. C., Hodge, P. Synthesis and Separation Lsing Fumctional Pofmers; John Wiley \& Sons: 1988.

14. Kim, T.-H.: Dokolas, P.: Feeder, N.: Giles, M.: Holmes, A. B. Chem. Conmum, 2000, 2419.

15. Kim, T.-H.: Giles, M.: Holmes, A. B. Chen. Conmm, 2000, 2421.

16. Seo, H. R.; Lee, H. K.; Jeon, S. Bull, Koreon Chem. Soc, 2004, 25 , 1484.

17. Lee, H. W.; Kishi, Y. J. Org. Chem. 1985, $50,4402$.

18. The reported yield $(48 \%)$ for the selective desilylation using TFA was rarely obtained in our hand as the orthoformate group was also cleaved under these conditions, and it was very diflicult to control the reaction. It should be also mentioned that direct carbonate formation of the inositol orthoformate 3 failed to give the desired compound 6 .

19. Billington, D. C.: Baker, R.; Kulagowski, J. J.: Mawer, I. M.; Vacca, J. P.: Desolms, S. J.: Hutr, J. R. J. Chem. Soc. Perkin Trans. $11989,1423$.

20. Corey, E. J.; Suggs, J. W. J. Org. Chem. 1973, 38, 3224.

21. Ireland, R. E.; Norbeck, D. W.J. Ant. Chem. Soce 1985, 107, 3279.

22. Homopolymerization of the carbonate monomer 10 only gave an insoluble product.

23. Full spectroscopic data, together with the conformational analysis by comparative spectroscopic methods of the polymers were reported: Kim, T.-H.; Holmes, A. B. J. Kor. Chem. Soc in press.

24. Comparison of the IR spectra of poly'ners and polychelates is ofter used to obtain information regarding the presence and or nature of chelation. For more infonnation and experimental details, see: Redds, A. V. R.: Reddy, P. S.; Reddy, G. H. Eum Polym. J. 1999, 35, 965. 